CDD: 025.48

\title{
O CONHECIMENTO PROFISSIONAL DO CATALOGADOR DE ASSUNTO SOBRE POLÍTICA DE INDEXAÇÃO EM BIBLIOTECAS UNIVERSITÁRIAS ${ }^{1}$
}

\section{THE PROFESSIONAL KNOWLEDGE OF SUBJECT CATALOGER INDEXING POLICY IN UNIVERSITY LIBRARIES}

\author{
Paula Regina Dal' Evedove ${ }^{2}$ \\ Mariângela Spotti Lopes Fujita ${ }^{3}$
}

\begin{abstract}
Resumo: Analisa-se o conhecimento profissional do catalogador de assunto acerca do papel da política de indexação no contexto de bibliotecas universitárias. Para tanto, o estudo compõe-se de aplicação de questionário e análise sóciocognitiva do conhecimento profissional de três catalogadores de assunto de distintas bibliotecas universitárias públicas do estado de São Paulo/Brasil por meio da aplicação de Protocolo Verbal em Grupo. Os resultados apontam que a catalogação de assunto deve estar respaldada por normas e diretrizes atualizadas que atendam as especificidades de cada contexto informacional e direcionem a prática cotidiana. Conclui-se que a carência de diretrizes direcionadas a normalização e/ou parâmetro teórico e metodológico do processo de catalogação de assunto é um dos principais pontos a serem observados pela literatura especializada em Ciência da Informação.
\end{abstract}

Palavras-chave: Política de indexação. Catalogador de assunto. Bibliotecas universitárias. Conhecimento profissional.

Abstract: Analyzes the professional knowledge of the subject cataloger about the role of indexing policy in the context of university libraries. Therefore, the study consists of a questionnaire and sociocognitive analysis of the professional knowledge of three subject catalogers of different university libraries in the state of São Paulo / Brazil, through the application of Verbal Protocol Group. The results indicate that the subject's cataloging must be supported by current standards and guidelines that address the specificities of each informational context and guide the daily practice. We conclude that the lack of guidelines aimed at standardizing and/or theoretical and methodological parameter of subject cataloging process is one of the main points to be observed by the specialized literature in Information Science.

Keywords: Indexing policy. Subject Cataloger. University Libraries. Professional Knowledge.

\footnotetext{
${ }^{1}$ Este trabalho encontra fundamento na Dissertação de Mestrado em Ciência da Informação defendida por Paula Regina Dal' Evedove na UNESP/Campus de Marília em 2010, sob orientação da Profa. Dra. Mariângela Spotti Lopes Fujita e com o financiamento da Fundação de Amparo à Pesquisa do Estado de São Paulo - FAPESP.

${ }^{2}$ Doutoranda do Programa de Pós-Graduação em Ciência da Informação da Faculdade de Filosofia e Ciências da Universidade Estadual Paulista, Campus de Marília. E-mail: p.dallevedove@ gmail.com

${ }^{3}$ Doutora em Ciências da Comunicação pela USP. Professora Titular do Departamento de Ciência da Informação da Faculdade de Filosofia e Ciências da Universidade Estadual Paulista, Campus de Marília. E-mail: fujita@marilia.unesp.br
}

Enviado em: 18/09/2012 - Aceito em: 28/02/2013 


\section{INTRODUÇÃO}

A informação impulsionou e continua a impulsionar o caminhar científico da Ciência da Informação na esfera dos aportes teóricos e aprofundamento de técnicas e instrumentos, objetivando-se o aperfeiçoamento da organização e representação da informação e do conhecimento em diferentes suportes e estruturas de armazenamento e recuperação da informação. Certamente, a pretensão do referido campo científico é algo complexo e permeado por indagações e desafios, o que culmina numa preocupação ativa em torno do profissional da informação e suas ações desempenhadas em contextos de trabalho constituídos por características e singularidades específicas, tal como o da biblioteca universitária.

A preocupação em torno do profissional da informação desencadeou a necessidade de observá-lo a partir de uma visão holística por meio do paradigma social ou construtivista, o qual propõe uma integração do ponto de vista cognitivo para uma abordagem sóciocultural mais ampla (HJØRLAND; ALBRECHTSEN, 1995; JACOB; SHAW, 1998; ØROM, 2000). Neste pensamento, o sujeito passa a ser considerado o centro do fenômeno informacional e, consequentemente, passa-se a considerar sua opinião, necessidades, problemas e visões de mundo enquanto elementos significantes e influentes no processamento da informação.

Com base no exposto, acredita-se que a opinião profissional é de grande valia para o estabelecimento e avaliação de diretrizes direcionadas a realização do tratamento temático da informação, considerando-se a carência de diretrizes direcionadas a normalização e/ou parâmetro teórico e metodológico do processo em contexto de bibliotecas universitárias. Isto porque, muitas das ações subjetivas e particulares dos profissionais da informação decorrem da falta de instrumentos e parâmetros direcionados para a realidade da prática profissional, esta altamente dependente do contexto de informação em que o profissional está inserido.

Portanto, entende-se que o processo de tratamento temático da informação deve estar calcado sob o prisma de uma política de indexação consistente e pertinente com a realidade própria do contexto de bibliotecas universitárias, em virtude de tais diretrizes atuarem como componente fundamental no que tange a produção de bens e serviços na esfera organizacional, bem como de formação cultural e social para a memória institucional. Ademais, o papel do profissional bibliotecário deixa de ser 
passivo, apenas organizando as informações. Hoje, o profissional da informação apresenta-se enquanto elemento fundamental para a coletivização do conhecimento e promoção social, cujas necessidades, opiniões e problemas relacionados ao saber (aportes teóricos) e ao fazer (prática cotidiana) devem ser considerados.

Neste sentido, o presente estudo visa analisar o conhecimento profissional do bibliotecário acerca do papel da política de indexação no contexto de bibliotecas universitárias. Com esta perspectiva, o estudo compõe-se de aplicação de questionário e análise sóciocognitiva do conhecimento profissional de catalogadores de assunto ${ }^{4}$ de distintas bibliotecas universitárias públicas do estado de São Paulo/Brasil por meio da aplicação de Protocolo Verbal em Grupo.

\section{PRESSUPOSTOS TEÓRICOS}

O papel da informação enquanto componente básico para o progresso da sociedade, agregado a incansável produção científica, desencadeou a transformação das bibliotecas em unidades não apenas detentoras, mas disseminadoras do saber humano. Na atual conjuntura, a principal função das bibliotecas é o fornecimento de informações relevantes a uma determinada comunidade usuária, cujas mudanças ocorridas na sociedade apontam a necessidade emergente de se criarem novos métodos que explorem e contribuam para as atividades realizadas ao tratamento e organização da informação documental, e que sejam adequados às necessidades de cada contexto informacional.

Nessa perspectiva, o papel das bibliotecas universitárias é atender as necessidades informacionais da comunidade acadêmica, diferindo-se dos demais contextos informacionais em virtude de ter como base do planejamento à educação e seus usuários serem heterogêneos. Assim, caracteriza-se por centrar "[...] seus objetivos nas necessidades informacionais do indivíduo, membro da comunidade universitária” (KLAES, 1991, p. 14) difundindo o conhecimento, bem como disponibilizando e tornando acessível todo o tipo de informação que venha em um

\footnotetext{
4 Adota-se o termo 'catalogador de assunto' e não 'indexador' em virtude do processo de tratamento temático da informação em contexto de bibliotecas universitárias ser realizado pela catalogação de assunto, a qual esta "[...] essencialmente ligada à construção de catálogos de bibliotecas e a indexação, por sua vez, à construção de índices de bibliografias em serviços de informação que produzem bases de dados" (RUBI, 2008, p.32).
} 
determinado momento contribuir na formação profissional, científica e cultural de sua comunidade.

Esses domínios informacionais distinguem-se por duas razões especiais: desenvolvem ações, produtos e serviços direcionados a um público específico; e são detentores de propriedades intelectuais, materiais e organizacionais que atuam para o desempenho de funções direcionadas ao desenvolvimento da sociedade. Fujita (2005) destaca que a biblioteca universitária atua como um espiral de evolução científica e tecnológica ao tornar-se consciente de sua função intermediária entre os processos documentais e a preservação e disseminação da informação com fins de geração de conhecimento. São, por excelência, contextos disseminadores do 'saber' desenvolvido nos domínios de conhecimento específicos de cada Universidade. Assim, potencializam o processo de transformação da informação em conhecimento.

Por ser uma organização dinâmica, a biblioteca universitária busca de maneira contínua aprimorar suas atividades tendo em vista as necessidades informacionais dos seus usuários, as quais devem ser sanadas de maneira rápida e precisa. Neste entendimento, os produtos e serviços oferecidos devem caracterizar-se pelo dinamismo dos processos e excelência em seus resultados. Sendo instituições dedicadas à acumulação e transmissão de conhecimento e informação, elas dissimulam "[...] uma concepção implícita de cultura, do saber e da memória, bem como da função que lhes cabe na sociedade de seu tempo". (JACOB, 2001). Na visão de Miksa (1992), a biblioteca universitária é uma instituição social e um processo de movimento da informação como um sistema de comunicação humana.

Tais colocações chamam a atenção para a importância de o profissional bibliotecário ser responsável por suas ações cotidianas a partir de reflexões recursivas sobre as circunstâncias do contexto de trabalho, em que,

A codificação e decodificação de contexto permitem ao sujeito compreender seu lugar na construção do conhecimento, num movimento de representação e análise crítica da situação codificada, o que propicia sua mobilização em novos contextos, possibilitando a intervenção na realidade, constituindo-se competência crítico-analítica de apreender uma representação da realidade para discussão, o que possibilita a construção de um novo conhecimento. (VARELA, 2008, p. 40). 
Neste sentido, verifica-se que "a eficácia no tratamento da informação depende, em grande parte, da forma com que ele é administrado e do bom entendimento de certos conceitos e relações". (FREITAS; KLADIS, 1995, p. 1). Sob este entendimento, os profissionais bibliotecários devem primar por um adequado tratamento da informação com um grau de seriedade e competência que assegure à biblioteca universitária, na figura do sistema e dos usuários, um eficaz suporte de recuperação da informação.

Considerando que a competência é um entendimento prático de uma determinada situação que se apóia num corpo de conhecimentos adquiridos ao longo dos anos, acredita-se que o profissional bibliotecário deva ser um agente competente no que tange ao processo de tratamento temático da informação, uma vez que a competência é um entendimento prático de uma determinada situação que se apóia num corpo de conhecimentos adquiridos ao longo dos anos. A competência profissional é um atributo latente, porém circunstancial, pois o ser competente exige determinadas ações específicas em um contexto de atuação. Portanto, o profissional bibliotecário precisa conhecer o contexto de informação para em seguida se adaptar as contingências específicas da diversidade de situações para uma efetiva intervenção e solução de problemas. (VARELA; BARBOSA, 2007).

Dudiziak (2007) aponta que existem diferentes níveis de competências informacionais, próprias para cada necessidade e contexto, sendo estas: nível básico organizar e localizar a informação a partir do domínio pleno na alfabetização tecnológica; nível secundário - acionar processos cognitivos para incorporar habilidades e conhecimentos construídos por meio da reflexão, com vistas ao uso, localização e organização da informação e sua posterior transformação em conhecimento; e nível complexo - construir significados acrescidos da noção de valores a partir da tríade informação, conhecimento e aprendizagem. Mediante tais considerações, o profissional bibliotecário precisa estar ciente de que no decorrer das etapas do processo de tratamento temático da informação ele constrói e desconstrói, acresce e modifica, complementa e altera o conhecimento por meio de seus processos cognitivos. Assim, todo profissional bibliotecário envolvido nesta atividade deve possuir bem mais que uma 'noção' de suas ações cotidianas em um contexto de informação; precisa atuar de maneira consciente. 
Inevitavelmente, o entendimento do contexto de informação implica no conhecimento dos fatos subjacentes, pois no que tange as práticas profissionais, “[...] novas funções surgiram e outras continuam surgindo, ligadas à intercessão de diferentes áreas do conhecimento”. (JAMBEIRO, 1998, p. 3), o que reforça a crença de que hoje a dicotomia entre 'teórico e prático' perde sentido quando alicerçados numa prática científica em que não é mais possível e aceitável diferenciá-los, pois só funcionam conjuntamente. Portanto, o profissional bibliotecário que realiza o processo de tratamento temático da informação em contexto de bibliotecas universitárias deve conhecer o todo do ciclo informacional - da produção ao uso da informação, considerando-se que a organização da informação não é uma atividade deslocada da realidade.

Para tanto, autores como Carneiro (1985); Rubi (2004, 2008, 2010); Rubi e Fujita (2007); Fujita, Rubi e Boccato (2009); Dal' Evedove (2010, 2011) dentre outros, defendem que o processo de tratamento temático da informação deve estar calcado sob o prisma de uma política de indexação atual que considere as necessidades e especificidades próprias do contexto de bibliotecas universitárias. Além disso, sua importância no contexto de bibliotecas universitárias decorre de seus objetivos, quais sejam: dar visibilidade na recuperação da informação; e identificar condutas teóricas e práticas das equipes de tratamento da informação (FUJITA; RUBI; BOCCATO, 2009).

De modo geral, a política de indexação consiste na forma de se realizar o tratamento temático da informação e no esforço por concretizar, sistematizar e representar em manuais os processos seguidos (GIL LEIVA, 2008). Portanto, deve ser vista como uma "[...] filosofia pertinente aos objetivos de recuperação da informação e não somente como uma lista de procedimentos a serem seguidos [...]” (RUBI; FUJITA, 2006, p. 49), pois compreendem um conjunto de procedimentos, materiais, normas e técnicas orientadas por decisões que refletem a prática e princípios teóricos da cultura organizacional.

\section{PROCEDIMENTOS METODOLÓGICOS}

O estudo, de caráter exploratório, analisou o conhecimento profissional de bibliotecários catalogadores de assunto acerca do papel da política de indexação em 
contexto de bibliotecas universitárias. Para tanto, o desenvolvimento da pesquisa de campo constou de coleta de dados por meio da aplicação de questionário e da técnica introspectiva do Protocolo Verbal, especificamente na modalidade de Protocolo Verbal em Grupo.

As referidas técnicas foram aplicadas com três catalogadores de assunto de distintas bibliotecas universitárias públicas do estado de São Paulo/Brasil. Os questionários foram enviados eletronicamente aos sujeitos participantes, sendo composto por três questões abertas. A elaboração e aplicação do questionário permitiram avaliar o modo pelo qual cada profissional percebe o papel da política de indexação no contexto das bibliotecas universitárias investigadas. Por sua vez, a escolha da técnica de Protocolo Verbal reside na compreensão de que, para se realizar estudo focado em um contexto informacional específico, torna-se necessário o levantamento de dados do ambiente em análise. Isto porque, a modalidade de Protocolo Verbal em Grupo inclui dados gerados a partir das manifestações espontâneas dos sujeitos participantes em eventos de leitura para observação da cognição e conhecimentos socialmente construídos.

Basicamente, o Protocolo Verbal em Grupo consiste na reunião de pessoas sujeitos participantes e pesquisador (a) para a leitura colaborativa de determinado texto e discussão de temas suscitados pelo mesmo. Nesta modalidade, o (a) pesquisador (a) interage como um dos sujeitos participantes apenas no intuito de controlar o gravador.

Para este estudo foram utilizados os seguintes procedimentos metodológicos de aplicação do Protocolo Verbal em Grupo, a saber:

$\checkmark \quad$ Procedimentos anteriores à coleta de dados

Definição do universo da pesquisa

A técnica foi aplicada com bibliotecários catalogadores de assunto que atuam em diferentes bibliotecas universitárias do estado de São Paulo de caráter público, sendo uma localizada na capital e as demais situadas no interior do estado. 
Seleção do texto-base

O texto-base utilizado foi selecionado por abordar o tratamento temático da informação na concepção da literatura especializada em Ciência da informação. Contudo, a fim de evitar uma leitura extensa das partes, selecionou-se o trecho entre as páginas 27 e 31, por conter os principais aspectos da sistematicidade do processo e serem pertinentes à discussão, a qual traria à tona as principais reflexões e conhecimentos dos sujeitos participantes acerca do papel da política de indexação em contexto de bibliotecas universitárias.

Referência:

DIAS, Eduardo Wense; NAVES, Madalena Martins Lopes. O processo de tratamento temático. In: Análise de assunto: prática e teoria. Brasília: Thesaurus, 2007. p. 27-31 (Estudos Avançados em Ciência da Informação, 3).

\section{Definição da tarefa}

Os tópicos abordados durante a coleta de dados dizem respeito aos objetivos a serem alcançados com base nos seguintes questionamentos: O porquê da presente pesquisa? Quais informações deverão ser obtidas? Qual tópico pretende-se abordar? Esclarece-se que os profissionais foram reunidos e observados por uma das pesquisadoras durante a aplicação da técnica, cuja participação foi moderada, ora interagindo com o grupo, ora conduzindo a discussão para que o texto fosse discutido por todos os sujeitos e não houvesse dispersão do assunto abordado.

\section{Seleção dos sujeitos participantes}

Para este estudo foram selecionados três catalogadores de assunto que realizam o processo de tratamento temático da informação em contexto de bibliotecas universitárias.

\section{Conversa informal com os sujeitos participantes}

\begin{tabular}{l|l|l|l|l|l|l|}
\hline (C) Rev. digit. bibliotecon. cienc. inf. & Campinas, SP & v.11 & n.2 & p. 21-39 & maio/ago. 2013 & ISSN 1678-765X \\
\hline
\end{tabular}


Realizou-se uma conversa informal com o responsável por cada biblioteca universitária, a qual resultou na aceitação e definição da data para a realização da coleta de dados. Posteriormente, no momento da aplicação do Protocolo Verbal em Grupo os sujeitos participantes foram recepcionados, ocorrendo um momento de apresentação entre as partes. Em seguida, foram mencionados os objetivos e a importância do estudo no âmbito da Ciência da Informação. Neste ponto, esclareceuse que todas as identidades dos sujeitos participantes seriam mantidas ocultas, a fim de não comprometer-lhes e, também, para que ficassem mais a vontade durante toda a aplicação da técnica.

$\checkmark \quad$ Procedimentos durante a coleta de dados

Gravação do "Pensar Alto" durante a discussão do Texto-Base

A realização da leitura e discussão do texto-base foi gravada por meio de um gravador digital.

\section{Entrevista retrospectiva (opcional)}

Após o término da aplicação da técnica introspectiva do Protocolo Verbal em Grupo foi realizada uma entrevista retrospectiva com os sujeitos participantes no intuito de esclarecer possíveis dúvidas sobrepostas durante a execução da atividade em análise.

$\checkmark \quad$ Procedimentos posteriores à coleta de dados

Transcrição literal das gravações das falas dos sujeitos participantes

Nesta etapa realizou-se a transcrição literal das falas com a identificação das fontes individuais de cada sujeito participante. Contudo, todas as falas foram enumeradas em turnos e divididas em unidades de análise, o que facilitou a análise e manteve a natureza contínua da interação entre os sujeitos. 
Leitura detalhada dos dados em busca de fenômenos significativos e recorrentes para a construção das categorias de análise

Efetuou-se uma leitura detalhada da transcrição do Protocolo Verbal em Grupo a fim de buscar aspectos relevantes para a construção das categorias de análise. Esta etapa foi baseada na leitura para observação.

Construção das categorias de análise

Após leitura detalhada dos dados coletados, construíram-se as categorias de análise que, por sua vez, constituem as unidades de análise por meio das quais as informações obtidas foram estruturadas e analisadas.

Releitura dos dados coletados

Realizou-se uma releitura da transcrição da coleta de dados com intuito de retirar trechos da discussão que melhor exemplificassem cada um dos fenômenos abordados nas categorias de análise.

\section{RESULTADOS E DISCUSSÃO}

A partir da análise dos dados coletados por meio da aplicação de questionário e Protocolo Verbal em Grupo obtiveram-se os seguintes resultados, a saber:

- Quanto ao questionário:

1. A instituição possui uma política de indexação regulamentada?

Apenas um dos três catalogadores de assunto investigados apontou a existência de uma política de indexação regulamentada, apesar do documento não estar publicado. 
2. Em sua opinião, quais seriam os benefícios oriundos do estabelecimento de uma política de indexação específica para o contexto de bibliotecas universitárias?

Todos os profissionais investigados acreditam que o estabelecimento de uma política de indexação acarreta maior consistência e uniformidade aos produtos e serviços da biblioteca universitária. Sobre isto, os Catalogadores de assunto $A$ e $B$ ressaltaram que seria uma maneira eficaz de conjugar a prática cotidiana com a teoria do tratamento temático da informação. No entendimento do Catalogador de assunto $C$ uma política de indexação clara e bem definida propicia uma maior padronização, além de ser uma rica fonte de consulta para nortear as ações cotidianas. Em sua opinião, a política de indexação contribui para aprimorar os níveis de desempenho profissional. Ademais, o referido sujeito entende a importância da prática profissional ser direcionada por diretrizes específicas, as quais contribuem com a melhoria da qualidade dos produtos e serviços oriundos do tratamento temático da informação em contextos de bibliotecas universitárias.

3. Em sua opinião, quais aspectos deveriam ser contemplados pela política de indexação?

O Catalogador de assunto $B$ acredita que o principal elemento a ser contemplado pela política de indexação seja uma orientação clara sobre o tratamento dos distintos suportes informacionais, respeitando suas características e peculiaridades. Para os Catalogadores de assunto $A$ e $C$ a política de indexação deve enfatizar a etapa da análise de assunto devido à subjetividade do processo.

De modo geral, os sujeitos investigados mostraram-se conscientes sobre a necessidade de se estabelecer uma política de indexação a fim de avaliar as ações profissionais e apontar se a prática cotidiana atende as necessidades dos usuários e corresponde com sua formação acadêmica. As respostas obtidas por meio dos questionários mostram que a principal preocupação dos catalogadores de assunto investigados decorre da inexistência de um nível de padronização do processo de tratamento temático da informação em contexto de bibliotecas universitárias. 


\section{- Quanto ao Protocolo Verbal em Grupo:}

Os dados seguem a indicação dos catalogadores de assunto com o propósito de evidenciar cada uma das partes envolvidas na discussão. Dentre todas as verbalizações transcritas, expõem-se apenas aquelas que melhor explicitam o temário abordado, a saber:

\section{- $\quad$ Unidade de análise 1 - Política de indexação}

Um dos catalogadores de assunto investigados apontou que o contato com as normas e diretrizes não é algo constante em sua prática cotidiana. Em decorrência, pode-se inferir que a atividade do tratamento temático da informação fica comprometida, uma vez que o profissional passa a se utilizar do bom sendo para realizar o processo devido à inexistência ou falta do uso de diretrizes que orientem a prática cotidiana da profissão por meio de filosofias e parâmetros para a tomada de decisão, minimizando a subjetividade e incertezas (DAL' EVEDOVE, 2010).

Ao estar descrita e registrada em manuais, a política de indexação identifica condutas teóricas e práticas das equipes envolvidas no tratamento temático da informação, característica que permite definir um padrão de cultura organizacional coerente com a demanda da comunidade acadêmica interna e externa (RUBI, 2008). Quanto a isso, o catalogador de assunto deve compreender a política de indexação como um componente necessário para que o processo seja realizado de maneira a coligar em sua prática profissional os aportes teóricos e interesses da instituição a qual está vinculado, assumindo uma postura compromissada.

Infelizmente a política fica em segundo plano, porque quando eu entrei aqui, por exemplo, eu li todos os manuais, mas o meu contato com esses materiais foi apenas na primeira semana e depois é algo que fica esquecido. (Catalogador de assunto A).

Por sua vez, no entendimento de um dos catalogadores de assunto o apoio de manuais e demais instrumentos e diretrizes atuam como um respaldo necessário para 
a realização do processo com vistas à qualidade dos produtos e serviços gerados. Pode-se concluir que tal entendimento decorre do fato de que, ao serem consideradas guias mestras, as políticas ou diretrizes atuam como planos gerais de ação que orientam a tomada de decisão e proporcionam estabilidade à organização (ALMEIDA, 2000).

(...) não é uma tarefa fácil atribuir assuntos, mas com o respaldo teórico e o apoio dos manuais da instituição se torna algo prazeroso, porque você sente que terá um resultado positivo lá na frente, ou seja, que o usuário irá recuperar a informação desejada. (Catalogador de assunto B).

Os profissionais compreendem a importância da política de indexação como um direcionamento das ações cotidianas e como recurso eficaz para amenizar falhas profissionais. Sobre isto, ressalta-se que a política de indexação deve indicar e detalhar de forma clara e objetiva todos os procedimentos (análise, síntese e representação) a serem realizados pelo profissional durante o processo de tratamento temático da informação em contexto de bibliotecas universitárias. Como resultado, "a descrição dos procedimentos permitirá que um padrão mínimo seja seguido [...] auxiliando os bibliotecários e atuando também como um instrumento de formação em serviço" (RUBI, 2008, p.118).

Por mais que a gente se esforce, faça mesmo todo o processo, tudo o que está ao nosso alcance para atender de maneira satisfatória o usuário e deixar os produtos e serviços oferecidos pela biblioteca com certo padrão de qualidade, sempre existem muitas falhas, as quais poderiam ser amenizadas com essa política. (Catalogador de assunto B).

(...) uma política já iria mostrar o modo correto de fazer as etapas do processo. (Catalogador de assunto $\mathrm{C}$ ).

Os resultados apontam que a realidade prática é que leva a execução das operações do processo de tratamento temático da informação por parte dos profissionais. As ações cotidianas e o modo de interlocução no contexto de informação imprimem no catalogador de assunto o entendimento do processo realizado de modo intuitivo, sem respaldo teórico e metodológico. Tais aspectos evidenciam a importância do estabelecimento de uma política de indexação que ampare a prática profissional do bibliotecário sob a perspectiva teórica e, 
paralelamente, estabeleça um nível de uniformidade ao processo em contexto de bibliotecas de universidades.

A este respeito, pode-se dizer que uma das necessidades latentes em Ciência da Informação, especificamente no que tange a área de Organização e Representação do Conhecimento, assenta-se no estabelecimento de metodologias destinadas à atividade do tratamento temático da informação, uma vez que a prática profissional possui dispares comportamental, os quais acabam por influenciar de maneira negativa a recuperação dos documentos nos sistemas de informação.

\section{- $\quad$ Unidade de análise 2 - Política de indexação e o contexto profissional}

De modo geral, os catalogadores de assunto investigados refletem sobre o impacto de suas ações particulares no contexto de bibliotecas universitárias. Como consequência, os profissionais observaram muitas lacunas entre a prática cotidiana e a literatura especializada do tratamento temático da informação. Dentre estas carências, destaca-se a falta de parâmetros metodológicos que sane as dificuldades e especificidades do contexto de bibliotecas universitárias.

Por ser um trabalho não apenas técnico, mas intelectual é importante que essas políticas direcionadas ao tratamento do documento abrangem desde os campos, as etapas da atribuição dos assuntos, mas também a biblioteca (...). Retratar pontos como a cultura, o foco, o público, coisas que fazem parte da biblioteca e que influenciam no trabalho, seja antes, durante ou depois do tratamento técnico. (Catalogador de assunto A).

Talvez a biblioteca devesse criar algo mais atual, mais específico com a realidade em que trabalhamos, porque isso certamente faria com que os profissionais do tratamento técnico se sentissem mais seguros em realizar o processo, porque teriam um respaldo condizente com a realidade da biblioteca. (Catalogador de assunto A).

Sobre isto, ressalta-se a necessidade de políticas de indexação condizentes com a realidade do ambiente de trabalho, visto que estas atuam como base consistente da prática profissional. Desse modo, as características próprias do contexto de bibliotecas universitárias devem ser contempladas nessas políticas, visando atender a comunidade local na esfera profissional e usuária. Para tanto, a política de indexação deve ser vista como uma filosofia própria do contexto em que está inserida, no intuito 
de refletir os interesses e objetivos específicos da biblioteca universitária enquanto organização (RUBI et al., 2007).

$\mathrm{Na}$ visão dos profissionais investigados, a política de indexação mostra-se necessária, a fim de propiciar um grau mais elevado de padronização e qualidade ao bojo dos produtos e serviços gerados no contexto de bibliotecas universitárias. No que tange a importância da adoção de critérios de qualidade do processo com fins de recuperação futura, Rubi (2008, p. 57) advoga que a política de indexação precisa ser entendida em âmbito global e, principalmente, em nível local, em que as particularidades de cada biblioteca universitária devem estar representadas e respeitadas de acordo com a demanda, ou seja, estabelecer critérios de política que corresponda a cada realidade específica.

(...) nós nunca paramos para discutir sobre a questão da política mesmo, o que seria um ganho se tivéssemos uma especifica para a nossa realidade, ou mesmo uma que pelo menos diminuísse toda essa dificuldade que é tratar e conseguir atender o usuário e o sistema (...), conseguir atrelar as duas realidades ao mesmo tempo. (Catalogador de assunto $\mathrm{B}$ ).

Neste momento de reflexão sobre a ação de catalogar no contexto de bibliotecas universitárias, torna-se eminente reforçar a importância do trabalho do catalogador de assunto, o qual deve estar respaldado por normas e diretrizes atualizadas que atendam as especificidades de cada contexto informacional e direcionem as ações cotidianas. Este entendimento está reiterado em Almeida (2007, p.74) quando afirma que a política de indexação visa “[...] obter, a partir da gestão da informação registrada, a visibilidade na recuperação da informação, bem como identificar condutas teóricas e práticas das equipes de tratamento da informação [...]". Assim, a realidade própria das bibliotecas universitárias deve ser considerada e contemplada na política de indexação, a fim de atender as necessidades específicas do contexto.

\section{CONSIDERAÇÕES FINAIS}


Os resultados obtidos neste estudo indicam a necessidade de diretrizes que subsidiem a atuação dos catalogadores de assunto em contexto de bibliotecas universitárias a fim de atenuar as ações profissionais pautadas no uso do bom senso e proporcionar, paulatinamente, uniformidade ao processo. Este pensamento respaldase na influência que a política de indexação acaba por exercer na esfera organizacional, seja relativo a informação propriamente dita, considerando sua organização, armazenamento, disseminação e uso; quanto na esfera do corpo profissional envolvido.

Entende-se que o estabelecimento de uma política de indexação atual e bem definida é uma maneira eficaz de se conjugar a prática cotidiana com os aportes teóricos, propiciar uma maior padronização aos produtos e serviços informacionais gerados em contexto de bibliotecas universitárias, bem como ser uma rica fonte de consulta para nortear as ações cotidianas dos catalogadores de assunto. Quando bem elaborada, a política de indexação assegura confiabilidade ao bojo das atividades informacionais que, inevitavelmente, respaldam na qualidade dos produtos e serviços gerados.

Com base nas opiniões dos catalogadores de assunto investigados neste estudo, julga-se relevante que os seguintes aspectos sejam considerados no estabelecimento de uma política de indexação condizente com a realidade do contexto de bibliotecas universitárias: no âmbito da informação documental - retratar e regulamentar as etapas do processo de tratamento temático da informação e; padronizar as metodologias de organização e representação da informação assegurando um equilíbrio entre coordenação, controle e descentralização da informação para o fortalecimento da disseminação e do intercâmbio informacional entre instituições cooperantes. Na esfera da atuação profissional, a política de indexação deve situar as redefinições das práticas profissionais no âmbito do processo de tratamento temático da informação no intuito de possibilitar mudanças estruturais na formação em serviço e na concepção dos perfis profissionais; e configurar a atividade profissional a partir dos objetivos específicos e da realidade própria do contexto de informação. No âmbito do contexto organizacional, a política de indexação precisa assegurar um planejamento adequado que contemple todo o 
contexto de informação, objetivando-se salvaguardar a memória e a cultura institucional.

\section{REFERÊNCIAS}

ALMEIDA, D. P. R de. Educação continuada em tratamento de conteúdos documentários: uma proposta de formação em serviço para bibliotecários catalogadores da rede de bibliotecas da UNESP. 2007. 413f. Tese (Doutorado em Ciência da Informação) Faculdade de Filosofia e Ciências, Universidade Estadual Paulista, Marília, 2007.

ALMEIDA, M. C. B. de. Planejamento de bibliotecas e serviços de informação. Brasília: Briquet de Lemos, 2000.

CARNEIRO, M. V. Diretrizes para uma política de indexação. Revista da Escola de Biblioteconomia da UFMG, Belo Horizonte, v. 14, n. 2, p. 221-241, set. 1985.

DAL' EVEDOVE, P. R. A perspectiva sóciocognitiva no tratamento temático da informação em bibliotecas universitárias: aspectos inerentes a percepção profissional. 2010. 300f. Dissertação (Mestrado em Ciência da Informação) - Faculdade de Filosofia e Ciências, Universidade Estadual Paulista, Marília, 2010.

DAL' EVEDOVE, P. R. A Política de Tratamento da Informação na Percepção de Catalogadores de Assunto. In: XXIV CONGRESSO BRASILEIRO DE BIBLIOTECONOMIA E DOCUMENTAÇÃO - CBBD, 2011, Maceió - AL. XXIV CBBD Anais: Sistemas de informação, multiculturalidade e inclusão social. Brasília: FEBAB, 2011. p. 1-12.

FREITAS, H. M. R.; KLADIS, C. M. Da informação à política informacional das organizações: um quadro conceitual. São Paulo - SP: RAP, v. 29, n. 3, p. 73-86, 1995.

FUJITA, M. S. L. Aspectos evolutivos das bibliotecas universitárias em ambiente digital na perspectiva da rede de bibliotecas da UNESP. Informação \& Sociedade: Estudos, João Pessoa, v. 15, n.2, p. 1-10, 2005.

FUJITA, M. S. L.; RUBI, M. P.; BOCCATO, V. R. C. O contexto sociocognitivo do catalogador em bibliotecas universitárias: perspectivas para uma política de tratamento da informação documentária. Datagramazero (Rio de Janeiro), v. 10, p. 06, 2009.

GIL LEIVA, I. Manual de indización: teoría y práctica. Gijón: Trea, 2008. 429 p.

GIL LEIVA, I.; RUBI, M. P.; FUJITA, M. S. L. Consistência na indexação em bibliotecas universitárias brasileiras. Transinformação, v. 20, p. 233-253, 2008.

HJØRLAND, B.; ALBRECHTSEN, H. Toward a New Horizon in Information Science: Domain-Analysis. Journal of the American Society for Information Science - JASIS, v. 46, n. 6, p. 400-425, 1995. 
JACOB, C. O poder das bibliotecas: a memória dos livros no Ocidente. Rio de Janeiro: UFRJ, 2001. $351 \mathrm{p}$.

JACOB, E. K.; SHAW, D. Sociocognitive perspectives on representation. In: WILLIANS, M.E. (Ed.). Annual Review of Information Science and Technology. Medford, NJ:

Information Today for American Society for Information Science, v. 33, p. 131-185. 1998.

JAMBEIRO, O. Gestão e tratamento da informação na sociedade tecnológica. São Paulo em Perspectiva, v. 12, n. 4, p. 3-10, 1998.

KLAES, R. R. Dados e informações usadas na tomada de decisão em bibliotecas universitárias brasileiras: o contexto da atividade de desenvolvimento de coleções. 1991. Dissertação (Mestrado em Biblioteconomia e Documentação) - Faculdade de Estudos Sociais Aplicados, Universidade de Brasília, 1991.

MIKSA, F. L. Library and information science: two paradigms. In: VAKKARI, P.; CRONIN, B. (ed.). Conceptions of library and information science: historical, empirical and theoretical perspectives. Proceedings of the International Conference held for the celebration of 20th Anniversary of the department of information studies. London: Taylor Graham, p. 229-252, 1992.

ØROM, A. Information science, historical changes and social aspects: a nordic outlook. Journal of Documentation, v. 56, n. 1, p. 12-26, 2000.

RUBI, M. P. A política de indexação na perspectiva do conhecimento organizacional. 2004. Dissertação (Mestrado em Ciência da Informação) - Faculdade de Filosofia e Ciências, Universidade Estadual Paulista, Marília, 2004.

RUBI, M. P.; FUJITA, M. S. L. La política de indización en la perspectiva del conocimiento organizacional. In: Blanca Rodríguez Bravo; Maria Luisa Alvite Diez. (Org.). La interdisciplinariedad y la transdisciplinariedad en la organización del conocimiento científico. León: Universidad de León, 2007, v. 1, p. 451-458.

RUBI, M. P.; FUJITA, M. S. L. O ensino de procedimentos de política de indexação. Perspectivas em Ciência da Informação, Belo Horizonte, v. 11, n.1, p. 48-66, 2006.

RUBI, M. P. et al. Política del tratamiento de la información documentaria en bibliotecas universitarias: estudio diagnóstico del contexto en la perspectiva del catalogador y del usuario. // Garcia Marco, F, J. (Org.). (2007). Avances y perspectivas en sistemas de información y documentación y en entorno digital. Zaragoza: Prensas Universitarias de Zaragoza, v. 1, p.71-80, 2007. Disponível em:

<http://www.ibersid.eu/ojs/index.php/ibersid/article/view/3262/3023>. Acesso em 15 de abr. de 2010.

RUBI, M. P. Política de indexação. In: Mariângela Spotti Lopes Fujita. (Org.). A indexação de livros: a percepção de catalogadores e usuários de bibliotecas universitárias. São Paulo: Cultura Acadêmica, 2010, p. 89-97.

RUBI, M. P. Política de indexação para construção de catálogos coletivos em bibliotecas universitárias. 2008. 169f. Tese (Doutorado em Ciência da Informação) - Faculdade de Filosofia e Ciências, Universidade Estadual Paulista, Marília, 2008. 
VARELA, A.; BARBOSA, M. L. A. Aplicação de teorias cognitivas no tratamento da informação. Revista Brasileira de Biblioteconomia e Documentação, Nova Série, São Paulo, v. 3, n. 2, p. 116-128, 2007. Disponível em: <http://rbbd.febab.org.br/rbbd/article/view/65>. Acesso em: 23 de jan. de 2009.

VARELA, A. Informação, cognição e mediação: vertentes, contextos e pretextos. Revista Ibero-americana de Ciência da Informação (RICI), v. 1, n. 1, p. 21-45, 2008. Disponível em: <http://seer.bce.unb.br/index.php/RICI/article/view/1541>. Acesso em: 12 de out. de 2010.

\section{Como citar este artigo:}

DAL' EVEDOVE, Paula Regina; FUJITA, Mariângela Spotti Lopes. O conhecimento profissional do catalogador de assunto sobre política de indexação em bibliotecas universitárias. Rev. digit. bibliotecon. cienc. inf., Campinas, SP, v. 11, n. 2, p.21-39, maio/ago. 2013. ISSN 1678-765X. Disponivel em: <http://www.sbu.unicamp.br/seer/ojs/index.php/rbci> 